\title{
Relationship Between Osteoporosis and Marginal Bone Loss in Osseointegrated Implants: A 2-Year Retrospective Study
}

José R. Corcuera-Flores, * Ana M. Alonso-Domínguez,* M. Ángeles Serrera-Figallo, * Daniel Torres-Lagares, ${ }^{*}$ Lizett Castellanos-Cosano, ${ }^{*}$ and Guillermo Machuca-Portillo*

Background: Fitting implants in osteoporotic patients has traditionally been controversial, and there is little scientific evidence relating osteoporosis to marginal bone loss (MBL). The aims of this study are as follows: 1 ) to evaluate the possibility of a correlation between osteoporosis, as measured by the mandibular cortical index (MCI), and $\mathrm{MBL}$ and 2) to assess how various systemic diseases, periodontitis, and placement of implants in regenerated bone are correlated with $\mathrm{MBL}$ and $\mathrm{MCI}$.

Methods: This retrospective study examines 212 implants inserted in 67 patients. To take a possible cluster failure into account, an implant for each patient was selected ( $n=67 \mathrm{im}$ plants). MBL was assessed. Osteoporosis was evaluated using the MCI. Both MBL and $\mathrm{MCI}$ were assessed from panoramic radiographs. $\chi^{2}$ test was performed (Haberman post hoc test). Significance was $P<0.05$.

Results: When the total sample implant $(N=212)$ was evaluated, a significant association was found between the presence of osteoporosis and $\mathrm{MCI}(P<0.001)$ and between the presence of diabetes mellitus and $\mathrm{MCI}(P<0.01)$. Significant associations were also found between MBL and placement of implants in regenerated sites $(P<0.001)$ and between $\mathrm{MBL}$ and a previous history of periodontitis $(P<0.05)$. When the sample is evaluated only in selected implants (one per patient, $n=67$ ), significant differences appear to relate only to the MBL with the placement of implants in regenerated bone sites $(P<0.001)$.

Conclusions: Osteoporosis (as evaluated by $\mathrm{MCI}$ ) does not pose a risk for the development of greater MBL. Parameters adversely affecting the development of increased MBL are a previous history of periodontitis and especially the placement of implants at sites of bone regeneration. J Periodontol 2016;87: $14-20$.

\section{KEY WORDS}

Bone regeneration; disease; osteoporosis; peri-implantitis; periodontal disease.

* Faculty of Odontology, University of Seville, Seville, Spain.
$\mathrm{O}$ steoporosis is defined as a systemic metabolic disease in which patients have low bone mass and display defects in bone microarchitecture. ${ }^{1}$ This increases bone fragility and can lead to a higher risk of fractures. ${ }^{1}$

Although the study of bone density remains the "gold standard" for assessing whether a patient has osteoporosis or not, a recent study on osteoporotic females with pathologic bone fractures demonstrate that osteoporosis can be identified reliably in a panoramic radiograph ${ }^{2}$ by using radiomorphometric indices such as the mandibular cortical index (MCI). This index allows patients to be categorized into three groups according to their degree of osteoporosis: 1) those with no bone pathology (C1), 2) the osteopenia group (C2), and 3) the osteoporosis group (C3). ${ }^{3}$

Peri-implantitis was first described by Mombelli et al. ${ }^{4}$ in 1987 as infectious and pathologic changes in peri-implant tissues. It can be diagnosed clinically (bleeding on probing, probing depth [PD] $>5 \mathrm{~mm}$, or three or more implant threads exposed $)^{5,6}$ or radiologically (marginal bone loss [MBL]). MBL is defined as bone loss around the implant, and this study is based on that variable.

It should be noted that bone loss of $0.2 \mathrm{~mm}$ around implants in the first year is considered normal. ${ }^{7}$ Subsequently, bone 
loss of $0.1 \mathrm{~mm}$ per year on its own does not constitute any peri-implant disease. ${ }^{7}$

Clinically, an implant is diagnosed with peri-implantitis in the presence of pocket bleeding, $\mathrm{PD}>6 \mathrm{~mm}$, or suppuration of peri-implant tissues. ${ }^{4,8,9}$ There are also radiologic methods for evaluating peri-implantitis based on MBL: some researchers used MBL from the implant shoulder $(>1 \mathrm{~mm})$ as a reference; ${ }^{10}$ others use the number of implant threads not in contact with bone ${ }^{11}$ (which might lead to confusion when different implant designs are evaluated); whereas others use a method based on MBL according to implant length. ${ }^{8}$

The classification described by Lagervall and Jansson ${ }^{9}$ is one of the most useful and reproducible for the radiologic detection of MBL. Risk factors for peri-implantitis include the presence of periodontal disease, poor plaque control, remnants of cement in the peri-implant sulcus, and diabetes. ${ }^{12}$

Numerous studies have established some relationship between alveolar and systemic bone loss related to measurements in the second metacarpal bone density in the hip or generalized bone mass. These comparisons have expanded to include titanium implants in the oral cavity versus those in the hip, but the comparison would not be accurate because dental implants are subject to the action of bacteria of the oral cavity, and those in the hip are not. In terms of tension and mechanical load, the circumstances could be considered similar, ${ }^{13}$ but several studies demonstrate a negative correlation between dental implant failure and osteoporosis. ${ }^{14-16}$ Dvorak et al. ${ }^{17}$ and Máximo et al. ${ }^{18}$ have studied the correlation between peri-implantitis and osteoporosis, and their results are inconclusive. Periimplantitis might also be related to other factors, such as periodontal disease and guided bone regeneration (GBR) at the implant site, ${ }^{19-21}$ and to other systemic diseases, such as diabetes ${ }^{8}$ and cardiovascular disease. 22,23

The aims of this study are as follows: 1) to evaluate the possibility of a correlation between osteoporosis (MCI) and MBL and 2) to assess whether various systemic diseases, periodontitis, and placement of implants in regenerated bone are correlated with either MBL or MCI.

\section{MATERIALS AND METHODS}

A retrospective study was conducted at the School of Dentistry of the University of Seville (Seville, Spain), with the approval of the Seville University Ethics Committee.

Two hundred twelve implants were inserted in 67 patients treated as part of the master's degree course in Integrated Dentistry in Adults and Special Patients at the University of Seville and had at least 2 years of loading. From those 67 patients, 134 panoramic radiographs were obtained: one just after placement of the implant and another 2 years later to look for changes in MBL. These panoramic radiographs were used to analyze MCI to evaluate osteoporosis.

\section{Inclusion and Exclusion Criteria}

Sixty-seven patients ( 31 males and 36 females; aged 30 to 81 years; mean age: 65.2 years) are included in the study and have implants placed (subgingival design that lacked a polished neck, placed at bone level and covered by the gingiva, or supragingival design having a smooth neck to allow healing without being submerged, 3.3, 4.1, and $4.8 \mathrm{~mm}$ wide and 8, 10, and $12 \mathrm{~mm}$ long, from the same company with the same surface $)^{\dagger}$ and loaded, with at least 2 years of loading. No short implants ( $<8 \mathrm{~mm}$ long) were used in any situation. To assess whether there were differences between the two types of implants when comparing the results with each variable, a comparative study between the two types was conducted.

Patients with diabetes were treated with oral antidiabetic agents, and those who had osteoporosis were treated with hormone replacement therapy, calcitonin, parathyroid hormone, and strontium ranelate. Patients were excluded if they were on medication that might affect bone metabolism (bisphosphonates and longterm corticosteroid treatment) and if their implants were not loaded or had been loaded for $<1$ year. Implants were not fitted in patients with periodontitis until all sites had been reassessed positively, 6 months after periodontal treatment.

To be included in the study, all the clinical data (e.g., diabetes and osteoporosis) had to be backed up by a medical report, as is required in the Department of Odontology in Special Patients.

To take a possible cluster failure into account, an implant for each patient was randomly selected according to the following procedure: 1 ) generation of a randomly assigned number ( 0 or 1 ) for each patient; 2) determination of the implant chosen for each patient from the previous random number and the number of implants per patient; 3) assignment of a sequential order of implants for each patient; 4) identification of the implant chosen in the second point; and 5) selection of the sample. As a result, 67 implants were selected (52 supragingival design and 15 subgingival design). To study the variability in the results, the same statistical procedure performed previously on all implants was applied to the selected implants.

\section{Primary Dependent Variable}

MCI is a qualitative radiomorphometric index that categorizes patients into three different groups according to their osteoporosis status. It is assessed from the inferior mandibular cortex and has been tested as a reliable method for the early diagnosis of osteoporosis. ${ }^{2}$ It is assessed as follows: 1 ) C1, in which

† ITI Implants, Institute Straumann, Basel, Switzerland. 

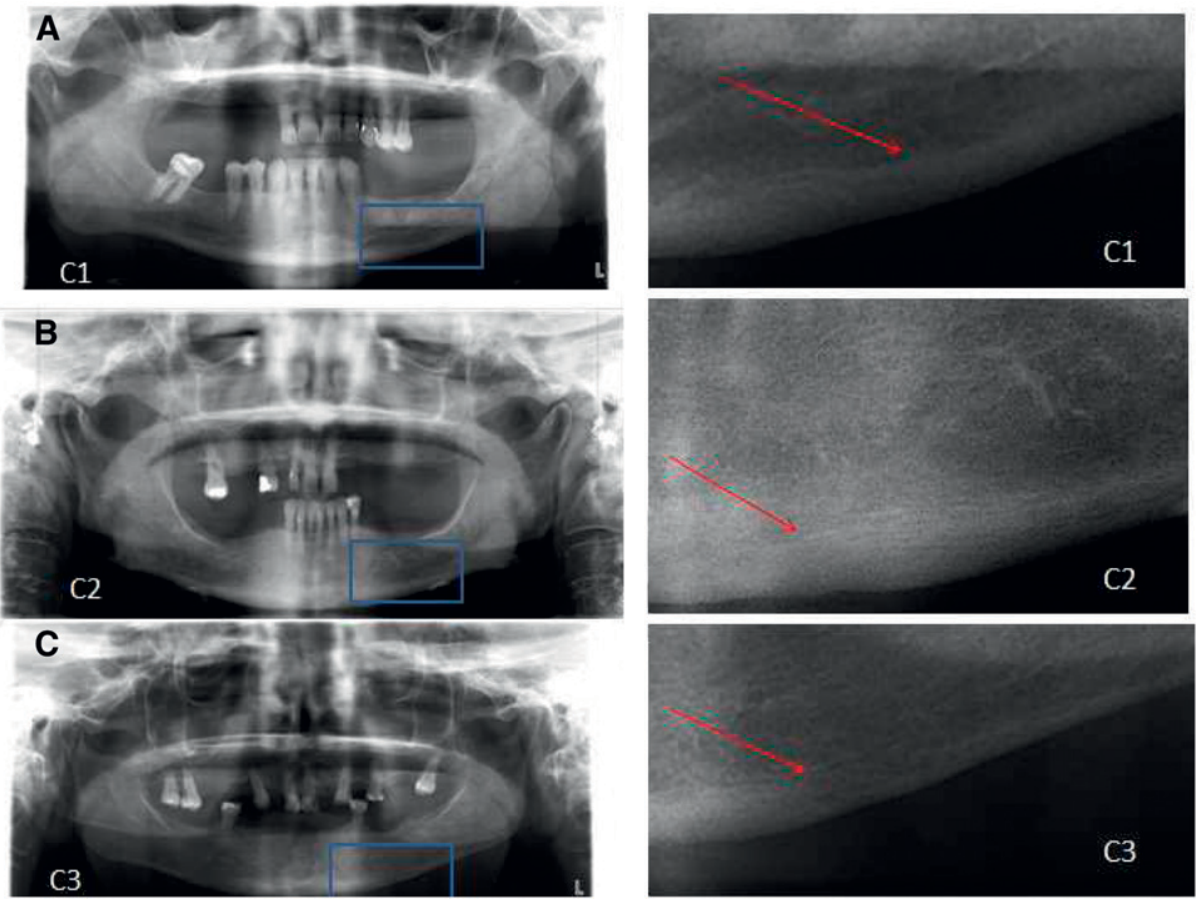

Figure I.

Panoramic radiographs and detailed views showing different degrees of osteoporotic bone impairment. A) The endosteal margin of the cortex is even and sharp on both sides (indicating a healthy bone structure, $\mathrm{CI}$ ). B) The endosteal margin shows semilunar defects (lacunar resorption) or appears to form endosteal cortical residues (one to three) on at least one side (indicating osteopenia, C2). C) The cortices are clearly porous on both sides (indicating a well-established osteoporotic status, C3).

4 = implant loss (this category was added by the present authors).

Two panoramic radiographs were obtained ${ }^{\ddagger}$ (at 1:1 magnification) for each case history, one at the time of implant placement and another 2 years afterward. Positioning of the head and mouth within the instrument was controlled. Implants were compared in the two radiographs to observe MBL over the 2-year period and thus assign each implant to a category in the modified classification based on the study by Lagervall and Jansson. ${ }^{9}$ The last radiograph was also used to calculate $\mathrm{MCl}$. All measurements were made by a single examiner (JRCF), calibrated for both $\mathrm{MCl}$ and MBL. The calibration consisted of the measurement of all radiographs by a second examiner (AMAD) and determination of the correlation coefficient.

Bone regeneration. An equine bone paste and equine collagen membrane were used in all cases of patients treated with bone graft. A record was also made

the endosteal margin of the cortex is even and sharp on both sides; 2) C2, in which the endosteal margin shows semilunar defects (lacunar resorption) or appears to form endosteal cortical residues (one to three) on at least one side; and 3) $\mathrm{C} 3$, in which the cortices are clearly porous. If the $\mathrm{MCI}$ differs on the two sides of the inferior mandibular cortex, the patient is assigned the higher grade (Fig. 1).

\section{Dependent Variables}

The previous diagnosis of periodontitis was determined from PD $\geq 4 \mathrm{~mm}$, BOP, and clinical insertion loss $\geq 4 \mathrm{~mm}^{24}$

Demographic data (e.g., occupation and cultural level) were also collected.

MBL. The panoramic radiographs were also used to evaluate MBL. This measurement was performed using the Lagervall and Jansson ${ }^{9}$ classification, modified by the authors of this study (to include an additional category), to compare the two panoramic radiographs obtained from patients at the beginning and end of the study. This classification divides implants into different categories according to MBL around the implant: $0=$ no MBL; $1=\mathrm{MBL}$ of one third of implant length or less; $2=\mathrm{MBL}$ more than one third but less than two thirds; $3=\mathrm{MBL}$ of two thirds or more of implant length; and of whether implant placement involved bone regeneration.

\section{Statistical Evaluation}

All statistical procedures were performed with statistical software. $\S$ The frequency and percentage were used for the description of qualitative variables. The correlation coefficient was measured using the Spearman test. The comparison of qualitative data was performed using the $\chi^{2}$ test, applying Haberman post hoc test. Statistical significance indicated in the tables and in text is shown in the usual ranges. Statistical significance was set at $P<0.05$.

\section{RESULTS}

The evaluator (JRCF) had a correlation coefficient of 0.87 corresponding to a percentage of coincidence of $>90 \%$ (Spearman test).

Details of patients studied and implants fitted can be seen in Table 1. With one implant per patient selected, the sample was reduced to 67 implants.

Table 2 shows MBL and its relationship to other test variables (MCI, bone regeneration, and history of periodontal disease), taking one implant per patient

‡ ProMax, Planmeca, Roselle, IL.

$\S$ SPSS v.19.0 for Windows, IBM, Armonk, NY. 
Table I.

\section{Study Sample Data}

\begin{tabular}{|c|c|c|}
\hline Variable & Patients, n (\%) & Implants, n (\%) \\
\hline \multicolumn{3}{|l|}{ Sex } \\
\hline Males & $31(46.3)$ & $31(46.3)$ \\
\hline Females & $36(53.7)$ & $36(53.7)$ \\
\hline \multicolumn{3}{|l|}{ Age group (years) } \\
\hline$<60$ & $22(32.8)$ & $57(26.9)$ \\
\hline 60 to 70 & $28(41.8)$ & $107(50.5)$ \\
\hline$>70$ & $17(25.4)$ & $48(22.6)$ \\
\hline \multicolumn{3}{|l|}{$\mathrm{MCl}$ (Class) } \\
\hline $\mathrm{Cl}$ & $22(32.8)$ & $22(32.8)$ \\
\hline C2 & $36(53.7)$ & $28(41.8)$ \\
\hline C3 & $9(13.5)$ & $17(25.4)$ \\
\hline \multicolumn{3}{|l|}{$\mathrm{MCl}$ (Class) by sex } \\
\hline \multicolumn{3}{|l|}{ Males } \\
\hline $\mathrm{Cl}$ & || (35.5) & NR \\
\hline C2 & $19(61.3)$ & NR \\
\hline C3 & I (3.2) & NR \\
\hline \multicolumn{3}{|l|}{ Females } \\
\hline $\mathrm{Cl}$ & II (30.6) & NR \\
\hline$C 2$ & $17(47.2)$ & NR \\
\hline C3 & $8(22.2)$ & $N R$ \\
\hline \multicolumn{3}{|l|}{ Previous periodontal disease } \\
\hline Yes & $37(55.2)$ & $37(55.2)$ \\
\hline No & $30(44.8)$ & $30(44.8)$ \\
\hline \multicolumn{3}{|l|}{ Concomitant disease present } \\
\hline Yes & $54(80.6)$ & $54(80.6)$ \\
\hline No & $13(19.4)$ & $13(19.4)$ \\
\hline \multicolumn{3}{|l|}{ Implant type } \\
\hline Supragingival & NR & $52(77.6)$ \\
\hline Subgingival & $N R$ & $15(22.4)$ \\
\hline \multicolumn{3}{|l|}{ Type of loading } \\
\hline Overdenture & NR & $16(23.9)$ \\
\hline Multi-tooth fixed prosthesis & NR & $20(29.9)$ \\
\hline Single tooth & NR & $31(46.2)$ \\
\hline
\end{tabular}

NR $=$ not reported .

or the entire sample. In this sense, no statistical differences between MBL and MCI were established in either situation. However, the MBL was significantly associated with placement of the implant in regenerated bone $(P<0.001)$ in either situation and with the previous condition of periodontal disease $(P<0.05)$ only when taking the whole sample.

Table 3 shows the relationship between the MBL and implant type (supragingival or subgingival). As shown, when taking only 67 individuals or the total sample, statistically significant differences were not obtained.

Likewise, Table 4 shows the relationship between MCI and the presence of diabetes mellitus and osteoporosis, considering one implant per patient and the entire sample. In this regard, it is noteworthy that when the entire sample is taken, the MCI was significantly related to the condition of previous osteoporosis $(P<0.001)$ and diabetes mellitus $(P<0.01)$. When only 67 selected patients were taken, this statistical significance was lost.

\section{DISCUSSION}

Peri-implantitis is studied extensively in the literature, and there are various methods (clinical and radiologic) for diagnosing this condition. Among the factors and components that affect it, one of the most critical and well studied is MBL, which is why this is chosen as one of the test variables in this study.

Periapical radiography has been described as a more sensitive method for measuring $\mathrm{MBL}$, but $\mathrm{MCI}$ is described in panoramic radiographs. To minimize this loss of sensitivity, it was ensured that all radiographs were performed with the same panoramic radiographic imaging system and with the same positioning system. Although some researchers consider it more orthodox to make the control measurement after bone remodeling, others, such as Máximo et al. ${ }^{18}$ or LopezPiriz et al. ${ }^{25}$ start from the radiograph taken at the time of implant placement. The present study uses the latter method. Furthermore, all measurements were made by a single examiner, precalibrated for both $\mathrm{MCI}$ and MBL.

When MBL was tested against the presence of osteoporosis, as evaluated by $\mathrm{MCI}$, no correlation between the two variables was found, as in the studies by Dvorak et al. ${ }^{17}$ and Máximo et al. ${ }^{18} \mathrm{~A}$ limitation of both these studies is that osteoporosis status was evaluated by means of a questionnaire. In this study, osteoporosis is evaluated by MCI, which has been demonstrated to be useful for assessing osteoporosis in the literature by $>20$ studies $^{2,3,26,27}$ and confirmed in patients with pathologic bone fractures. Therefore, the conclusion reached in the present study carries more weight than the findings of the abovementioned studies, ${ }^{2}$ given that osteoporotic fracture represents the highest grade of osteoporosis, irrespective of the fracture patient's bone mineral density. Numerous studies have established some relationship between alveolar and systemic bone loss. Regarding the comparison of dental implants with those that could be placed in other parts of the body, such as the hip, it should be considered that the comparison would never be exact because dental implants are subject to the action of bacteria of the oral cavity. ${ }^{13}$

Many comparative studies of bone regeneration and implants are based on their stability. ${ }^{28,29}$ In a study by Deli et al., ${ }^{30}$ implants placed in sites of bone regeneration were found to offer less stability. However, stability is not the only implant characteristic examined in relation to bone regeneration. ${ }^{31}$ Quirynen et al. ${ }^{21}$ 
Table 2.

\section{Relationship Between MBL and Other Test Variables for One Implant per Patient and All of the Implants}

\begin{tabular}{|c|c|c|c|c|c|c|}
\hline \multirow[b]{2}{*}{ Variable } & \multicolumn{5}{|c|}{ MBL (Class) } & \multirow[b]{2}{*}{$P$} \\
\hline & 0 & I & 2 & 3 & 4 & \\
\hline \multicolumn{7}{|l|}{ One implant $(n=67)$} \\
\hline $\mathrm{MCl}$ Class & & & & & & NS \\
\hline 1 & $17(77.3)$ & $3(13.6)$ & $0(0.0)$ & I (4.5) & I (4.5) & \\
\hline 2 & $19(52.8)$ & $13(36.1)$ & $3(8.3)$ & $0(0.0)$ & I (2.8) & \\
\hline 3 & $5(55.6)$ & $3(33.3)$ & I (II.I) & $0(0.0)$ & $0(0.0)$ & \\
\hline GBR & & & & & & $<0.001$ \\
\hline Yes & $4(28.6) *$ & $6(42.9)$ & I (7.1) & I $(7.1)^{\dagger}$ & $2(14.3)^{*}$ & \\
\hline No & $37(69.8) *$ & $13(24.5)$ & $3(5.7)$ & $0(0.0)^{\dagger}$ & $0(0.0)^{*}$ & \\
\hline Previous periodontal disease & & & & & & NS \\
\hline Yes & $20(54.1)$ & | | (29.7) & $4(10.8)$ & I (2.7) & I (2.7) & \\
\hline No & $21(70.0)$ & $8(26.7)$ & $0(0.0)$ & $0(0.0)$ & I (3.3) & \\
\hline \multicolumn{7}{|l|}{ All implants $(N=212)$} \\
\hline $\mathrm{MCl}$ Class & & & & & & NS \\
\hline 1 & $46(60.5)$ & $23(30.3)$ & $2(2.6)$ & I (1.3) & $4(5.3)$ & \\
\hline 2 & $54(45.8)$ & $52(44.1)$ & $8(6.8)$ & $0(0.0)$ & $4(3.4)$ & \\
\hline 3 & $10(55.6)$ & $7(38.9)$ & I (5.6) & $0(0.0)$ & $0(0.0)$ & \\
\hline GBR & & & & & & $<0.001$ \\
\hline Yes & $10(23.8)^{\ddagger}$ & $24(57.1)^{*}$ & $4(9.5)$ & I $(2.4)^{\dagger}$ & $3(7.1)$ & \\
\hline No & $100(58.8)^{\ddagger}$ & $58(34.1)^{*}$ & $7(4.1)$ & $0(0.0)$ & $5(2.9)$ & \\
\hline Previous periodontal disease & & & & & & $<0.05$ \\
\hline Yes & $59(44.4)$ & $57(42.9)$ & $9(6.8)$ & I $(0.8)^{\dagger}$ & $7(5.3)$ & \\
\hline No & $51(64.6)$ & $25(31.6)$ & $2(2.5)$ & $0(0.0)$ & I (1.3) & \\
\hline
\end{tabular}

NS = non-significant.

All data presented as n (\%) implants.

* $P<0.01$, Haberman test.

$\dagger P<0.05$; Haberman test.

$\ddagger P<0.001$, Haberman test.

found that implants inserted in regenerated bone were 2.5 times more likely to fail. The present study tests different grades of MBL against implants placed in regenerated sites. A positive correlation was found between Class 1 and 3 MBL and GBR. This might suggest that, when placing implants in sites subjected to GBR, the clinician should conduct more frequent check-ups so that, if peri-implantitis occurs (being more likely to do so), it can be treated promptly.

There is scientific evidence for an association between peri-implantitis and active periodontitis. ${ }^{25}$ Casado et al. ${ }^{20}$ concluded that patients with a previous history of periodontal disease that had been treated and arrested had a four-fold higher risk of developing peri-implant disease. When all sample implants were taken, the present study finds a positive correlation between MBL and a previous history of periodontitis. By taking an implant per patient, statistical significance with respect to this parameter is lost. Although this sample is more specific, the low number seems to cause this disparity. With the entire sample, although less specific, the ratio of previous periodontitis to implant loss was $7 / 133$. In this sense, it is necessary to select a larger sample to confirm these findings. Regardless, this finding seems to support the evidence for an association between periodontitis and the development of peri-implantitis. ${ }^{32}$

Although quantitative methods would be more accurate, various studies have confirmed that $\mathrm{MCI}$ is a reliable method for diagnosing osteoporosis. ${ }^{27,33,34}$ In this study, it is chosen as the diagnostic method for osteoporosis because of its simplicity and reproducibility. ${ }^{35}$ Also, the same tool (panoramic radiography) could be used to evaluate osteoporosis and MBL.

A positive correlation was found between $\mathrm{MCI}$ and a previous diagnosis of osteoporosis, which is confirmed by several studies. ${ }^{2,3,26,36,37}$ When MCI was tested against the presence of diabetes mellitus, a positive correlation was found. This is consistent with the findings of Jackuliak and Payer, ${ }^{38}$ who found that osteoporosis had a higher prevalence among patients with diabetes. Diabetes mellitus is also positively correlated with a higher risk of osteoporotic fractures attributable to reduced bone strength in patients with diabetes. ${ }^{39}$ 
Table 3.

\section{Relationship Between MBL and Implant Design for One Implant per Patient and All of the Implants}

\begin{tabular}{|c|c|c|c|c|c|c|}
\hline \multirow[b]{2}{*}{ Implant } & \multicolumn{5}{|c|}{ MBL (Class) } & \multirow[b]{2}{*}{$P$} \\
\hline & 0 & । & 2 & 3 & 4 & \\
\hline One implant $(n=67)$ & & & & & & NS \\
\hline Supragingival & $33(63.5)$ & $13(25.0)$ & $4(7.7)$ & $0(0.0)$ & $2(3.8)$ & \\
\hline Subgingival & $8(53.3)$ & $6(40.0)$ & $0(0.0)$ & I (6.7) & $0(0.0)$ & \\
\hline All implants $(N=212)$ & & & & & & NS \\
\hline Supragingival & $96(53.9)$ & $65(36.5)$ & $10(5.6)$ & $0(0.0)$ & $7(3.9)$ & \\
\hline Subgingival & $14(41.2)$ & $17(50.0)$ & | (2.9) & I (2.9) & I (2.9) & \\
\hline
\end{tabular}

NS = non-significant.

All data presented as n (\%) implants.

Table 4.

Relationship Between MCI and Other Test Variables for One Implant per Patient and in All of the Implants

\begin{tabular}{|c|c|c|c|c|}
\hline \multirow[b]{2}{*}{ Implant } & \multicolumn{3}{|c|}{$\mathrm{MCl}$ (Class) } & \multirow[b]{2}{*}{$P$} \\
\hline & I & 2 & 3 & \\
\hline \multicolumn{5}{|l|}{ One implant $(n=67)$} \\
\hline Osteoporosis & & & & NS \\
\hline Yes & I (II.I) & $5(55.6)$ & $3(33.3)$ & \\
\hline No & $21(36.2)$ & $31(53.4)$ & $6(10.3)$ & \\
\hline Diabetes mellitus & & & & NS \\
\hline Yes & $4(26.7)$ & $10(66.7)$ & I (6.7) & \\
\hline No & $18(34.6)$ & $26(50.0)$ & $8(15.4)$ & \\
\hline \multicolumn{5}{|c|}{ All implants $(N=2 \mid 2)$} \\
\hline Osteoporosis & & & & $<0.001$ \\
\hline Yes & $2(10.0)$ & I| (55.0) & $7(35.0)$ & \\
\hline No & $74(38.5)$ & $107(55.7)$ & II (5.7) & \\
\hline Diabetes mellitus & & & & $<0.01$ \\
\hline Yes & $8(17.8)$ & $35(77.8)$ & $2(4.4)$ & \\
\hline No & $68(40.7)$ & $83(49.7)$ & $16(9.6)$ & \\
\hline
\end{tabular}

NS = non-significant.

All data presented as n (\%) implants.

Additional multicenter studies, in which the number of implants is increased, are needed to validate the results.

\section{CONCLUSIONS}

According to the results of this clinical study, it can be said that osteoporosis (as evaluated by $\mathrm{MCI}$ ) does not pose a risk for the development of greater MBL. Parameters adversely affecting MBL are a previous history of periodontal disease and especially the placement of implants at sites of bone regeneration.

\section{ACKNOWLEDGMENT}

The authors report no conflicts of interest related to this study.

\section{REFERENCES}

1. Copenhague-Consensus Development Conference. Consensus development conference: Prophylaxis and treatment of osteoporosis. Am J Med 1991;90:107-110.

2. Martínez-Maestre MA, Corcuera Flores JR, Machuca G, González-Cejudo C, Torrejón R, Castelo-Branco C. Panoramic radiomorphometry and vertebral fractures in Spanish postmenopausal women. Maturitas 2013;76:364-369.

3. Klemetti E, Kolmakov S, Kröger H. Pantomography in assessment of the osteoporosis risk group. Scand J Dent Res 1994;102:68-72.

4. Mombelli A, van Oosten MA, Schurch E Jr., Land NP. The microbiota associated with successful or failing osseointegrated titanium implants. Oral Microbiol Immunol 1987;2: 145-151.

5. Atieh MA, Alsabeeha NH, Faggion CM Jr., Duncan WJ. The frequency of peri-implant diseases: A systematic 
review and meta-analysis. $J$ Periodontol 2013;84: 1586-1598.

6. Peñarrocha-Diago M, Maestre-Ferrín L, Cervera-Ballester J, Peñarrocha-Oltra D. Implant periapical lesion: Diagnosis and treatment. Med Oral Patol Oral Cir Bucal 2012;17:e1023-e1027.

7. Rosen P, Clem D, Cochran D, et al. Peri-implant mucositis and peri-implantitis: A current understanding of their diagnoses and clinical implications. J Periodontol 2013;84: 436-443.

8. Venza I, Visalli M, Cucinotta M, De Grazia G, Teti D, Venza M. Proinflammatory gene expression at chronic periodontitis and peri-implantitis sites in patients with or without type 2 diabetes. J Periodontol 2010;81:99-108.

9. Lagervall M, Jansson LE. Treatment outcome in patients with peri-implantitis in a periodontal clinic: A retrospective study. J Periodontol 2013;84:1365-1373.

10. Yaşar $F$, Akgünlü $F$. The differences in panoramic mandibular indices and fractal dimension between patients with and without spinal osteoporosis. Dentomaxillofac Radiol 2006;35:1-9.

11. Serino G, Ström C. Peri-implantitis in partially edentulous patients: Association with inadequate plaque control. Clin Oral Implants Res 2009;20:169-174.

12. Koldsland OC, Scheie AA, Aass AM. Prevalence of periimplantitis related to severity of the disease with different degrees of bone loss. J Periodontol 2010;81:231-238.

13. Jeffcoat MK. Oral bone loss and systemic osteopenia: Potential treatment and risks. In: Marcus R, Feldman D, Nelson DA, Rosen CJ, eds. Osteoporosis, 3rd ed., vol. 2. Waltham, MA: Elsevier; 2008:1399-1415.

14. Friberg B, Ekestubbe A, Mellström D, Sennerby L. Brånemark implants and osteoporosis: A clinical exploratory study. Clin Implant Dent Relat Res 2001;3:50-56.

15. Becker W, Hujoel PP, Becker BE, Willingham H. Osteoporosis and implant failure: An exploratory case-control study. J Periodontol 2000;71:625-631.

16. Lindhe J, Meyle J; Group D of European Workshop on Periodontology. Peri-implant diseases: Consensus report of the sixth European workshop on periodontology. J Clin Periodontol 2008;35(Suppl. 8):282-285.

17. Dvorak G, Arnhart C, Heuberer S, Huber CD, Watzek G, Gruber R. Peri-implantitis and late implant failures in postmenopausal women: A cross-sectional study. $J$ Clin Periodontol 2011;38:950-955.

18. Máximo MB, de Mendonça AC, Alves JF, Cortelli SC, Peruzzo DC, Duarte PM. Peri-implant diseases may be associated with increased time loading and generalized periodontal bone loss: Preliminary results. J Oral Implantol 2008;34:268-273.

19. Wilson V. An insight into peri-implantitis: A systematic literature review. Prim Dent J 2013;2:69-73.

20. Casado PL, Pereira MC, Duarte ME, Granjeiro JM. History of chronic periodontitis is a high risk indicator for peri-implant disease. Braz Dent J 2013;24:136-141.

21. Quirynen M, Vogels R, Alsaadi G, Naert I, Jacobs R, van Steenberghe D. Predisposing conditions for retrograde peri-implantitis, and treatment suggestions. Clin Oral Implants Res 2005;16:599-608.

22. Renvert S, Polyzois I. Risk indicators for peri-implant mucositis: A systematic literature review. J Clin Periodontol 2015;42(Suppl. 16):S172-S186.

23. Gómez-de Diego R, Mang-de la Rosa M del R, RomeroPérez MJ, Cutando-Soriano A, López-Valverde-Centeno A. Indications and contraindications of dental implants in medically compromised patients: Update. Med Oral Patol Oral Cir Bucal 2014;19:e483-e489.
24. Buduneli N, Baylas H, Buduneli E, Türkoğlu O, Köse T, Dahlen G. Periodontal infections and pre-term low birth weight: A case-control study. J Clin Periodontol 2005;32: 174-181.

25. Lopez-Piriz R, Morales A, Giménez MJ, et al; SEIRN group. Correlation between clinical parameters characterising peri-implant and periodontal health: A practicebased research in Spain in a series of patients with implants installed 4-5 years ago. Med Oral Patol Oral Cir Bucal 2012;17:e893-e901.

26. Devlin H, Horner K. Mandibular radiomorphometric indices in the diagnosis of reduced skeletal bone mineral density. Osteoporos Int 2002;13:373-378.

27. Calciolari E, Donos N, Park JC, Petrie A, Mardas N. Panoramic measures for oral bone mass in detecting osteoporosis: A systematic review and meta-analysis. $J$ Dent Res 2015;94(Suppl. 3):17S-27S.

28. Kurra S, Fink DA, Siris ES. Osteoporosis-associated fracture and diabetes. Endocrinol Metab Clin North Am 2014; 43:233-243.

29. Becker W, Hujoel P, Becker BE, Wohrle P. Survival rates and bone level changes around porous oxide-coated implants (TiUnite ${ }^{\mathrm{TM}}$ ). Clin Implant Dent Relat Res 2013; 15:654-660.

30. Deli G, Petrone V, De Risi V, Tadic D, Zafiropoulos GG. Longitudinal implant stability measurements based on resonance frequency analysis after placement in healed or regenerated bone. J Oral Implantol 2014;40:438-447.

31. Fischer K, Bäckström M, Sennerby L. Immediate and early loading of oxidized tapered implants in the partially edentulous maxilla: A 1-year prospective clinical, radiographic, and resonance frequency analysis study. Clin Implant Dent Relat Res 2009;11:69-80.

32. Sgolastra F, Petrucci A, Severino M, Gatto R, Monaco A. Smoking and the risk of peri-implantitis. A systematic review and meta-analysis. Clin Oral Implants Res 2015;26:e62-e67.

33. Cakur B, Dagistan S, Sahin A, Harorli A, Yilmaz A. Reliability of mandibular cortical index and mandibular bone mineral density in the detection of osteoporotic women. Dentomaxillofac Radiol 2009;38:255-261.

34. Wilding RJ, Levin I, Pepper R. The use of panoramic radiographs to measure alveolar bone areas. $J$ Oral Rehabil 1987;14:557-567.

35. Taguchi A, Tsuda M, Ohtsuka M, et al. Use of dental panoramic radiographs in identifying younger postmenopausal women with osteoporosis. Osteoporos Int2006;17: 387-394.

36. Govindraju P, Chandra P. Radiomorphometric indices of the mandible - An indicator of osteoporosis. J Clin Diagn Res 2014;8:195-198.

37. Gaur B, Chaudhary A, Wanjari PV, Sunil M, Basavaraj P. Evaluation of panoramic radiographs as a screening tool of osteoporosis in post menopausal women: A cross sectional study. J Clin Diagn Res 2013;7:2051-2055.

38. Jackuliak P, Payer J. Osteoporosis, fractures, and diabetes. Int J Endocrinol 2014;2014:820615.

39. Nyman JS, Even JL, Jo CH, et al. Increasing duration of type 1 diabetes perturbs the strength-structure relationship and increases brittleness of bone. Bone 2011;48:733-740.

Correspondence: Prof. Guillermo Machuca-Portillo, Facultad de Odontología, C/ Avicena s/n., 41009 Sevilla, Spain. Fax: 34-954481131; e-mail: gmachuca@us.es.

Submitted April 8, 2015; accepted for publication August 5, 2015. 